\title{
Corrosion of chromium containing alloys in non-steady state environments containing oxygen, carbon, and chlorine
}

\author{
M.J. McNallan, S. Thongtem, J.C. Liu, Y.S. Park and P. Shyu
}

CEMM Dept., m/c 246, University of Illinois at Chicago, P.O. Box 4348, Chicago, IL 60680, U.S.A.

\begin{abstract}
Internal attack of chromium containing alloys in mixed oxygen-chlorine environments occurs by the formation of pores which penetrate down grain boundaries of the alloys. No internal attack was detected in a binary $\mathrm{Fe}-20 \% \mathrm{Cr}$ alloy at $1200 \mathrm{~K}$ in environments containing $2500 \mathrm{ppm} \mathrm{Cl} \mathrm{Cl}_{2}$. The rate of internal attack of alloy $800 \mathrm{H}$ in such environments was increased by replacing the $\mathrm{O}_{2}$ in the gas by $\mathrm{CO}_{2}$. In mixed oxygen-carbon-chlorine environments, the internal attack occurs by selective chlorination of chromium carbides which precipitate along the grain boundaries.
\end{abstract}

\section{Introduction.}

Alloys intended for sevice at elevated temperatures in reactive environments obtain their resistance to corrosion by the formation of a dense, adherent oxide layer which separates the metal from the environment [1]. Because chromium oxide has protective characteristics and is more thermodynamically stable than the oxides of iron, nickel or cobalt, chromium is the element which provides the oxidation resistance in many such alloys used in the range of 600 to $900^{\circ} \mathrm{C}$ [2].

In complex industrial environments which contain more than one oxidizing species, the protective character of the chromium oxide film may be compromised, and corrosion may occur at a higher rate than in only oxygen [3]. Chlorine is present in some high temperature environments produced during incineration of municipal and industrial wastes [4,5], waste heat recovery from chemical and metallurgical processes [6,7], and combustion or conversion of low quality chlorine "contaminated" fuels [8,9].

High temperature corrosion by chlorine differs from corrosion by other oxidizing gases because of the volatility of many chlorides and oxychlorides at elevated temperatures [10]. In mixed environments containing both oxygen and chlorine, the corrosion products can include both condensed species, typically oxides, and volatile species, typically chlorides or oxychlorides [11]. The kinetics of the overall corrosion process are determined by the order in which the corrosion products form and by the morphology of the condensed corrosion products [12]. The rate of mixed oxidation-chlorination may be higher or lower than the rate of oxidation in uncontaminated oxygen depending on the chemistry of the system and temperature [13-15].

In chromium containing alloys, the formation of a protective oxide scale occurs by selective oxidation. Fe-Cr alloys and Ni-Cr alloys can both be subject to accelerated oxidation in the presence of chlorine [16,17]. Chromium containing alloys are also subject to accelerated attack in mixed carbon-oxygen environments [18]. Carbon penetrates into the alloy and reacts 
with chromium to form chromium carbides preventing formation of a protective chromium oxide layer at the surface. Carbon is always present in combustion gases, so that corrosion in chlorine "contaminated" combustion gases is influenced by carbon, oxygen, and chlorine. This paper describes the results of experiments on iron-chromium and iron-nickel-chromium alloys in environments containing oxygen, carbon, and chlorine.

\section{Experimental details.}

Results on two alloys are described: A binary Fe-Cr alloy containing approximately $20 \% \mathrm{Cr}$ by weight, and the austenitic $\mathrm{Fe}-\mathrm{Ni}-\mathrm{Cr}$ alloy $800 \mathrm{H}$. The compositions of the two alloys are given in table I. The binary alloy had a composition close to that of AISI 430 stainless steel, but was prepared by induction melting electrolytic iron and chromium in air. It contained a higher concentration of the non-metal impurities nitrogen and oxygen and a correspondingly lower concentration of carbon than a commercial alloys.

Table I. - Alloy compositions (weight \%).

\begin{tabular}{|c|c|c|}
\hline & Fe-20\% Cr & Alloy 800H \\
\hline Element & & \\
\hline $\mathrm{Fe}$ & Balance & Balance \\
\hline $\mathrm{Ni}$ & - & 33 \\
\hline $\mathrm{Cr}$ & 19.02 & 21 \\
\hline $\mathrm{Al}$ & $<0.01$ & 0.38 \\
\hline $\mathrm{Ti}$ & - & 0.38 \\
\hline $\mathrm{C}$ & 0.01 & 0.08 \\
\hline $\mathrm{N}$ & 0.074 & - \\
\hline $\mathrm{O}$ & 0.10 & - \\
\hline
\end{tabular}

The alloys were exposed to corrosive gas mixtures containing: 1) argon, oxygen and chlorine or 2) argon, carbon dioxide and chlorine in the apparatus shown schematically in figure 1. Square test coupons approximately $1 \mathrm{~cm} \times 1 \mathrm{~cm} \times 1 \mathrm{~mm}$ were suspended from a fused silica rack in the center of a fused silica reaction tube. The reaction tube was heated to the test temperature using an electrical resistance furnace with Kanthal heating elements. To exclude air from the tube, it was closed at the bottom and sealed at the top by a water cooled brass cap. The spine of the sample rack was a fused silica tube which also carried the reactive gas mixture into the furnace. Gas mixtures were prepared by mixing technical grades of argon, oxygen, carbon dioxide and chlorine, supplied as mixture of argon $-3.5 \% \mathrm{Cl}_{2}$ by volume. The argon and oxygen were purified by passage through packed columns of anhydrous calcium sulfate for water removal and Ascarite for $\mathrm{CO}_{2}$ removal. The Ar-3.5 $\% \mathrm{Cl}_{2}$ mixture was dried in a column of anhydrous calcium sulfate. 


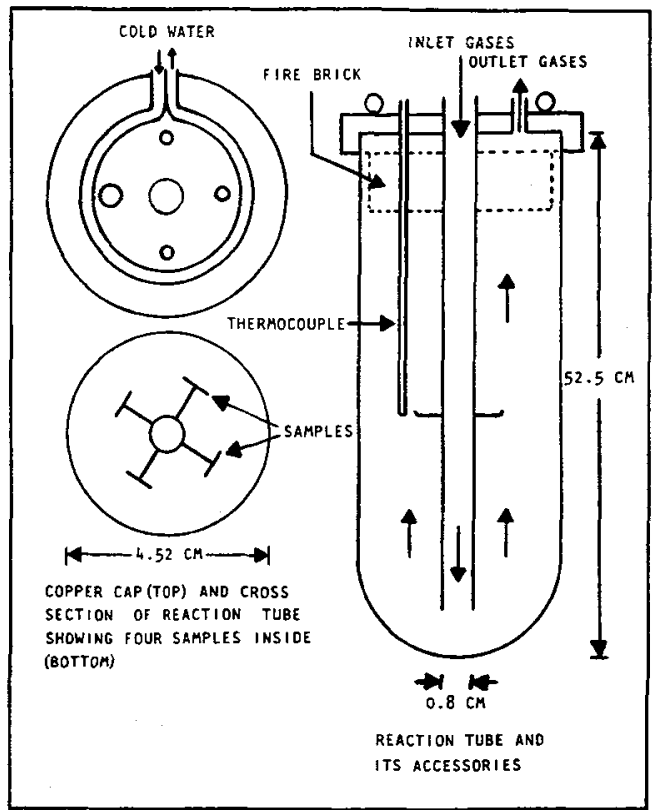

Fig. 1. - Schematic diagram of apparatus for long term testing of metal coupons in chlorine containing gas mixtures.

Experiments were initiated by suspending four specimens of the test alloy from the rack and purging the reaction tube with purified argon. The furnace was heated to the test temperature in this inert environment. When the temperature was stable, the argon was replaced by the corrosive gas mixture flowing at a velocity of $1.5 \mathrm{~cm} \mathrm{~s}^{-1}$ at the reaction temperature. After 50, 100, and 200 hours of exposure, the furnace was cooled to room temperature and one specimen was removed. The fourth specimen was removed after 400 hours of exposure.

After removal from the furnace, the specimens were weighed to determine the change in mass. They were then mounted and cross sectioned to determine the loss in section thickness and to characterize the internal attack by optical and electron microscopy.

\section{Results.}

$\mathrm{Ar}-\mathrm{O}_{2}-\mathrm{Cl}_{2}$ ENVIRONMENT. - Figure 2 shows the loss in section thickness from the $\mathrm{Fe}-20 \% \mathrm{Cr}$ and alloy $800 \mathrm{H}$ specimens tested in $\mathrm{Ar}-20 \% \mathrm{O}_{2}-2500 \mathrm{ppm} \mathrm{Cl}_{2}$ at $1200 \mathrm{~K}$. The mass changes in the specimens were appropriate to the changes in section thickness. The metal loss from the $\mathrm{Fe}-20 \% \mathrm{Cr}$ alloy was approximately parabolic with time as would be expected when a protective scale is formed, while that from the $800 \mathrm{H}$ alloy had a linear time dependence, but a significantly smaller total magnitude.

Specimens from the two alloys were examined for internal attack. None was detected in the $\mathrm{Fe}-20 \% \mathrm{Cr}$ alloys, while for the $800 \mathrm{H}$ alloy, internal corrosion was detected as shown in figure 3. The internal corrosion took the form of porosity along the grain boundaries of the alloy near the corroded surface. The depth of penetration of the internal corrosion from the surface of the specimen was a parabolic function of time as shown in figure 4 . 


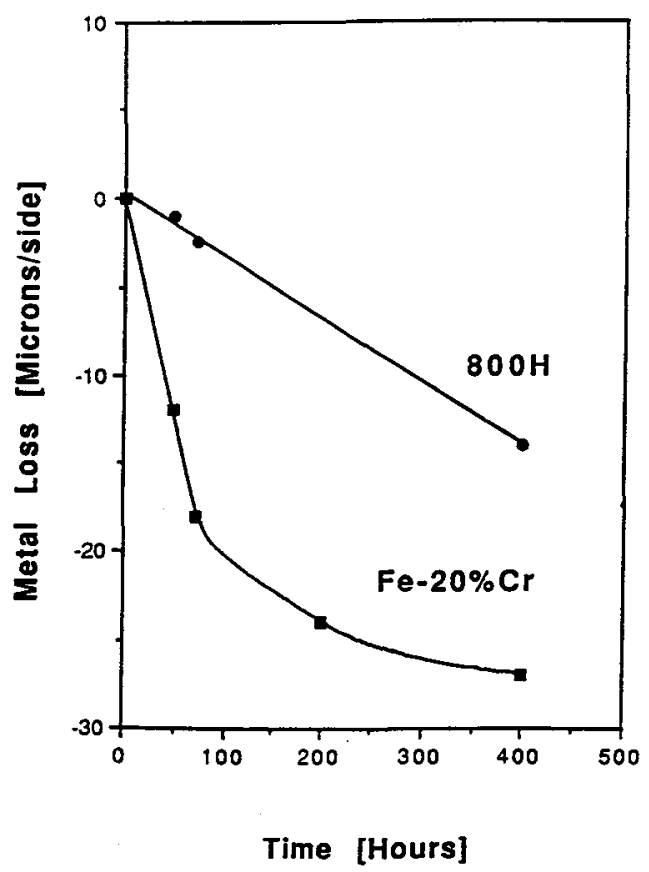

Fig. 2. - Loss in thickness versus time for $\mathrm{Fe}-20 \% \mathrm{Cr}$ and alloy $800 \mathrm{H}$ in $\mathrm{Ar}-20 \% \mathrm{O}_{2}-2500 \mathrm{ppm} \mathrm{Cl}_{2}$ at $1200 \mathrm{~K}$.

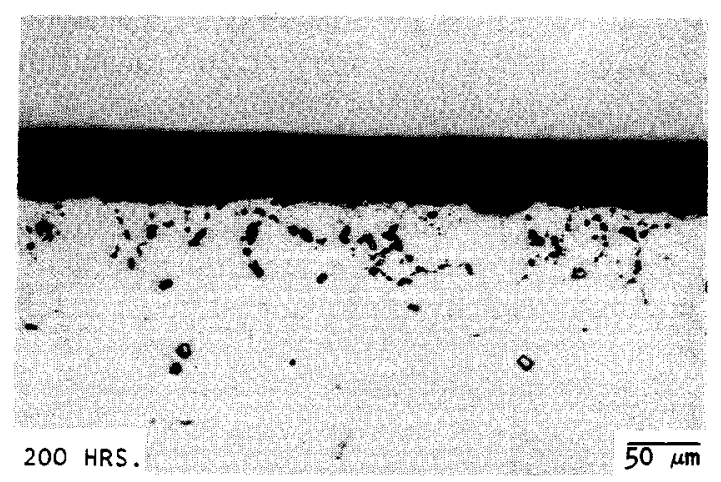

Fig. 3. - Internal corrosion in alloy $800 \mathrm{H}$ after 200 hours exposure to $\mathrm{Ar}-20 \% \mathrm{O}_{2}-2500 \mathrm{ppm} \mathrm{Cl} 2$ at $1200 \mathrm{~K}$.

Internal corrosion has also been observed in a number of commercial alloys exposed to mixed oxygen-chlorine gases at elevated temperatures [19,20]. The lack of internal corrosion in the binary alloy provoked interest in the role of carbon in the internal corrosion process. The binary alloy, which did not experience internal corrosion, differed from the commercial alloys in that it contained a lower concentration of carbon and it had a ferritic structure in which carbon has a lower solubility. 


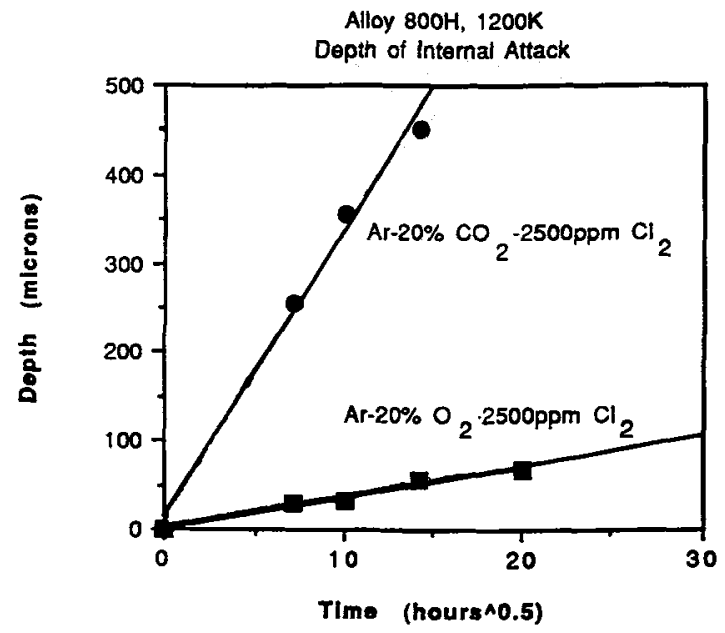

Fig. 4. - Internal attack of alloy $800 \mathrm{H}$ at $1200 \mathrm{~K}$ in $\mathrm{Ar}-20 \% \mathrm{O}_{2}-2500 \mathrm{ppm} \mathrm{Cl} 2$ and $\mathrm{Ar}-20 \% \mathrm{CO}_{2}-2500$ ppm $\mathrm{Cl}_{2}$.

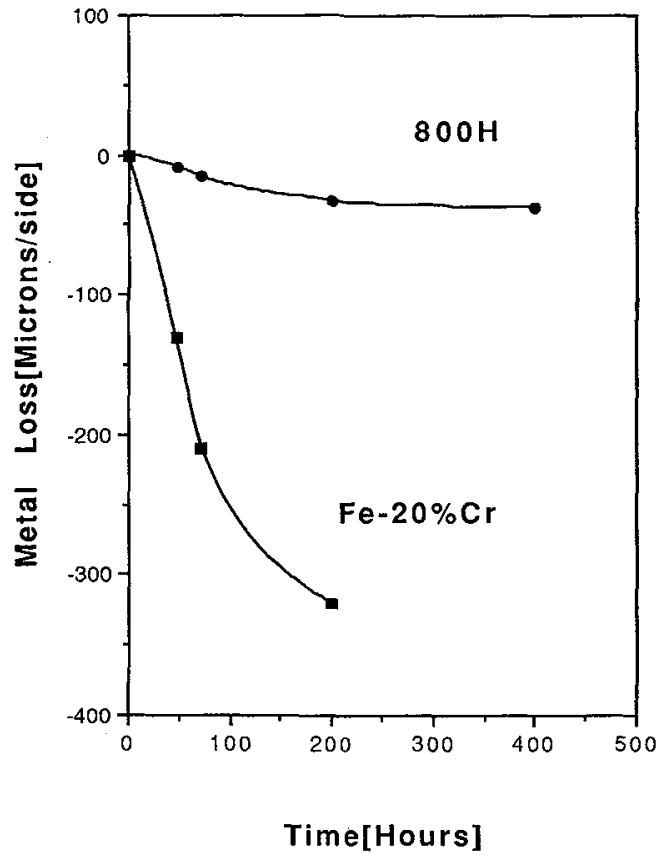

Fig. 5. - Loss in thickness versus time for $\mathrm{Fe}-20 \% \mathrm{Cr}$ and alloy $800 \mathrm{H}$ in $\mathrm{Ar}-20 \% \mathrm{CO}_{2}-2500 \mathrm{ppm} \mathrm{Cl}_{2}$ at $1200 \mathrm{~K}$.

Ar- $\mathrm{CO}_{2}-\mathrm{Cl}_{2}$ Environment. - Figure 5 shows the metal losses from the Fe-20\% $\mathrm{Cr}$ and $800 \mathrm{H}$ specimens exposed to $\mathrm{Ar}-20 \% \mathrm{CO}_{2}-2500 \mathrm{ppmCl}_{2}$ at $1200 \mathrm{~K}$. Both alloys were attacked much more rapidly in this gas mixture than in $\mathrm{Ar}-\mathrm{O}_{2}-\mathrm{Cl}_{2}$. The $\mathrm{Fe}-20 \% \mathrm{Cr}$ alloy specimen was completely consumed before the end of the 400 hour exposure but examination of the 


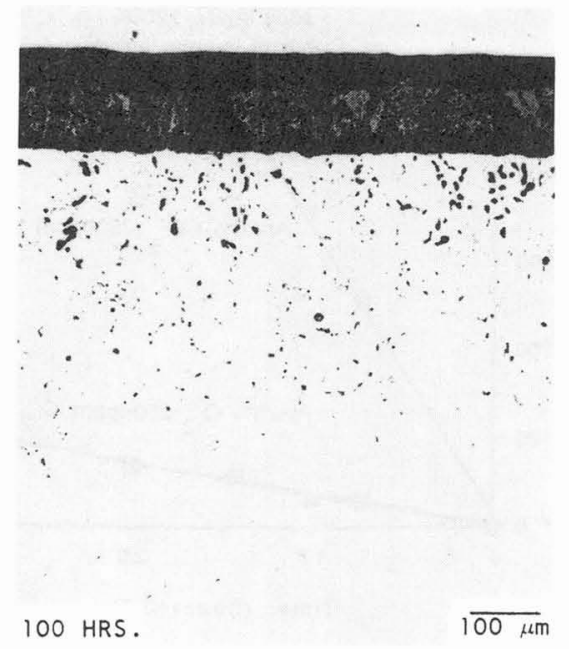

Fig. 6: - Internal corrosion in alloy $800 \mathrm{H}$ after 100 hours exposure to $\mathrm{Ar}-20 \% \mathrm{Co}_{2}-2500 \mathrm{ppm} \mathrm{Cl}_{2}$ at $1200 \mathrm{~K}$.

specimens exposed for shorter periods showed that there was no internal attack. The rate of consumption of the $800 \mathrm{H}$ specimen was substantially lower than that from the Fe-20\% Cr specimen, was a parabolic rather than linear function of time, but was still substantially higher than it had been in the environment which did not contain carbon.

In addition to the increased metal consumption, the $800 \mathrm{H}$ specimen also experienced accelerated internal attack as shown in figure 4 . The form of the internal corrosion was similar to that produced in $\mathrm{Ar}-20 \% \mathrm{O}_{2}-2500 \mathrm{ppm} \mathrm{Cl}$, as shown in figure 6 , but the depth of attack was much greater. After 400 hours of exposure, the internal corrosion had penetrated to the center of the specimen in some regions. The kinetics of the internal attack were also approximately parabolic as shown in figure 4 .

\section{Discussion.}

Although the overall rate of oxidation of the alloys was increased by the addition of chlorine to the oxidizing environments, internal corrosion was the primary focus of this work. No internal corrosion was found in the binary Fe-Cr alloy and the rate of internal attack in the commercial alloy $800 \mathrm{H}$ increased when carbon was present in the environment. The rate of internal attack of alloy $800 \mathrm{H}$ in the carbon containing environment was much higher than the rate of internal chloridation of a binary $\mathrm{Ni}-\mathrm{Cr}$ alloy at a similar temperature [21], indicating that the mechanism is more complex than simple internal chloridation. These results suggest that carbon plays a critical role in the internal attack of chromium containing alloys in chlorine containing environments at elevated temperatures.

The following mechanism is hypothesized for the internal corrosion: carbon contained in the environment dissolves in the alloy, and combines with chromium in the alloy to form chromium carbides at the grain boundaries. The surrounding grains are depleted in chromium. Chromium forms a more stable chloride than iron or nickel, and therefore the chlorine consumes the chromium carbides to form volatile chromium chlorides but its reaction 
with the surrounding metal is limited by the low chromium content of this metal. The corrosion takes the form of tortuous pores which follow the grain boundaries into the alloy. The volatile chlorides diffuse out of the alloy through the pores while the carbon combines with chromium in the alloy to form additional carbides on the grain boundaries ahead of the pores. The overall rate of the process is controlled by transport of chlorine and/or chlorides through the pores, leading to parabolic kinetics. A similar mechanism has been proposed to explain internal corrosion in cobalt based alloys in chloride containing molten salt environments [22].

The binary Fe-Cr alloy had a lower carbon content than the $800 \mathrm{H}$ and was ferritic at the test temperature. It experienced only external corrosion in both test environments. When the $800 \mathrm{H}$ was corroded in $\mathrm{Ar}-20 \% \mathrm{O}_{2}-2500 \mathrm{ppm} \mathrm{\textrm {Cl } _ { 2 }}$, the carbon content of the alloy was sufficient to cause chromium carbide precipitation on the grain boundaries and support internal corrosion. In $\mathrm{Ar}-20 \% \mathrm{CO}_{2}-2500 \mathrm{ppm} \mathrm{Cl}_{2}$, the additional carbon in the environment accelerated the internal attack.

\section{Conclusion.}

Internal corrosion of chromium containing alloys in chlorine containing environments is accelerated by the presence of carbon. Because carbon is present in most combustion environments, internal attack is likely to be more severe in such environments than would be expected based on laboratory studies performed in environments without carbon.

\section{Acknowledgements.}

This work has been sponsored by the Illinois Department of Energy and Natural Resources through its Coal Development Board and Center for Research on Sulfur in Coal.

\section{References}

[1] Kofstad P., High Temperature Corrosion (Elsevier Applied Science, Essex, U.K. 1988).

[2] WRIGHT I.G., Metals Handbook, 9th Edition, Vol 13, Corrosion (ASM International, Materials Park, OH, 1987) p. 97.

[3] Meier G.H., Birks N., Pettit F., Giggins G.S., High Temperature Corrosion, National Association of Corrosion Engineers, R.A. Rapp Ed. (Houston, TX, 1983).

[4] LAI G.Y., J. Met. 37 (1985) 14.

[5] Krause H.H., Vaughan D.A., Miller P.D., Trans. ASME, J. Eng. Power 96 (1974) 216-222.

[6] FEDERER J.I., JONES P.J., ORNL/TM-9741 (1985).

[7] Van Roode M., Price J.R., Gildersleeve R.E., Smeltzer C.E., Ceram. Eng. Sci. Proc. 9 (1988) 1245-1259.

[8] D. Bannerjee, J. Stringer Eds., Chlorine in Coal, Coal Science and Technology Series, 17 (Elsevier Science Publishers, Amsterdam, the Netherlands, 1991).

[9] Wright I.G., SETHI V.K., KrauSE H.H., STRINGER H., K. Natesan, D.J. Tillach Eds., Heat Resistant Materials (ASM International, Materials Park, OH, 1991) pp. 415-427.

[10] DANiEl P.L., RAPP R.A., M.G. Fontana, R.G. Staehle Eds., Advances in Corrosion Science and Technology, 5 (Plenum Press, New York, NY, 1976) pp. 55-176. 
[11] Jacobson N.S., MC Nallan M.J., Kreidler E.R., High Temp. Sci. 27 (1990) 381-392.

[12] Mc Nallan M.J., Liang W.W., OH J.M., Kang C.T., Oxid. Met. 17 (1982) 371-389.

[13] Maloney M.J., MC Nallan M.J., Metall. Trans. 16B (1985) 751-761.

[14] LEE Y.Y., MC NALlan M.J., Metall. Trans. 18A (1987) 1099-1107.

[15] LEE S.Y., MC NALLAN M.J., J. Electrochem. Soc. 137 (1990) 472-479.

[16] Kim A.S., MC NALLAN M.J., Corrosion 46 (1990) 746-755.

[17] MC Nallan M.J., Jacobson N.S., LEe Y.Y., Chang Y.W., DoyChaK J., J. Electrochem. Soc. 138 (1991) 3692-3696.

[18] Grabke H., Gravenhorst U., SteinkUSCH W., Werkst. Korros. 27 (1976) 291-296.

[19] OH J.M., MC Nallan M.J., Rothman M.F., Lai G.Y., Metall. Trans. 17A (1986) 10871094.

[20] Prescott R., Stott F.H., Elliott P., Oxid. Met. 31 (1989) 145-166.

[21] LI Y.K., RAPP R.A., Metall. Trans. 14B (1983) 509-510.

[22] El Dahshan M., Stringer J., WhitTle D.P., Cobalt 57 (1972) 182-191. 